\title{
Defensores de derechos humanos, obstáculo en la lucha antiterrorista
}

\author{
José Guillermo Carrillo Ballesteros*
}

* Máster Oficial en Estudios Avanzados en Derechos Humanos, Universidad Carlos III de Madrid, Madrid, España. Especialista en Derecho Procesal Penal, Universidad Cooperativa de Colombia y Especialista en Derecho Administrativo, Universidad Autónoma de Bucaramanga, Bucaramanga, Colombia. Profesor del Área de Derecho Público, Universidad Cooperativa de Colombia, Bucaramanga, Colombia. Correo electrónico: jose.carrillo@campusucc.edu.co

Recibido: 9 de marzo de 2014

Aprobado: 5 de mayo de 2014

\section{Cómo citar este artículo:}

José Guillermo Carrillo Ballesteros. Defensores de derechos humanos, obstáculo en la lucha antiterrorista. DIXI. Junio 2014.

Pág. 45. doi: http://dx.doi.org/10.16925/ di.v16i19.731

\begin{abstract}
Resumen
Después de los atentados terroristas del 11 de septiembre del 2001 en los Estados Unidos, del 11 de marzo del 2004 en Madrid y los de Londres el 7 y 21 de julio del 2005, la implementación de políticas antiterroristas y el fortalecimiento de la seguridad nacional se convirtieron en la prioridad de los Estados y, aunque legítima y necesaria, con el tiempo fue desviada de su objetivo principal, pasando a ser la "coartada" perfecta para que muchos Estados consolidaran su arsenal represivo y se afianzaran en el poder. En nombre de esta lucha, parecía ser que todos los abusos estaban justificados y pronto los métodos utilizados incrementaron las violaciones a los derechos humanos, aunque en este contexto de total represión, han sido las denuncias de los defensores de derechos humanos los que vienen logrando poner al descubierto los excesos y los abusos de poder, arriesgando incluso su vida y la de sus familias, siendo estigmatizados y su labor criminalizada, pasando de esta forma a convertirse para muchos Estados en verdaderos obstáculos frente a su lucha antiterrorista.
\end{abstract}

Palabras clave: criminalización, defensores de derechos humanos, estigmatización, judicialización, seguridad nacional, terrorismo.

Human Rights Defenders, an Obstacle in the Fight against Terrorism

\section{Abstract}

After the terrorist attacks of September 11, 2001 in the United States, March 11, 2004 in Madrid and those in London on July 7 and 21 of 2005, the implementation of antiterrorist policies and strengthening of national security became the priority of states, and while legitimate and necessary, over time this deviated from its main objective and became the perfect "alibi" to enable many states to consolidate their repressive arsenal and strengthen their power. In the name of this struggle, it would seem that all abuses were justified and the methods used soon gave rise to greater human rights violations. However, in this context of total repression, it has been the denunciations by human rights defenders that have revealed excesses and abuses of power. In doing so, they endanger themselves and their families, while suffering stigmatization and seeing their work criminalized. For many states, they thus become true obstacles in the fight against terrorism.

Keywords: criminalization, human rights defenders, stigmatization, prosecution, national security, terrorism.

DEFENSORES DE DIREITOS hUMANOS, OBSTÁCULO NA LUTA ANTITERRORISTA

Resumo

Depois dos atentados terroristas de 11 de setembro de 2001 nos Estados Unidos, de 11 de março de 2004 em Madrid e de 7 e 21 de julho de 2005 em Londres, a implementação de políticas antiterroristas e o fortalecimento da segurança nacional se converteram na prioridade dos Estados e, embora legítima e necessária, com o tempo foi desviada de seu objetivo principal, e passou a ser a "álibi" perfeita para que muitos Estados consolidassem seu arsenal repressivo e se consolidassem no poder. Em nome dessa luta, parecia ser que todos os abusos estavam justificados e logo os métodos utilizados aumentaram as violações aos direitos humanos. Ainda que nesse contexto de total repressão, são as denúncias dos defensores de direitos humanos que vêm conseguindo pôr em evidência os excessos e os abusos de poder, o que os leva a arriscarem sua vida e a de suas famílias, a serem estigmatizados e seu trabalho criminalizado, passando, dessa forma, a se converterem para muitos Estados em verdadeiros obstáculos ante sua luta antiterrorista.

Palavras-chave: criminalização, defensores de direitos humanos, estigmatização, judicialização, segurança nacional, terrorismo. 


\section{INTRODUCCIÓN}

La constante criminalización de los defensores de derechos humanos con el pretexto de la lucha antiterrorista y el fortalecimiento de la seguridad ciudadana hace que su labor, su vida y la de sus familias se encuentren en una situación de alto riesgo.

Se pretende, de esta forma, determinar cuál es ese tipo de riesgo que corren estos defensores cuando bajo la etiqueta de terroristas y la implementación de estas políticas su actividad es estigmatizada, criminalizada y judicializada.

Para esto, este artículo se estructuró en dos partes. En la primera se identifica el contexto en el que los derechos humanos han venido perdiendo terreno frente a la implementación de las políticas antiterroristas y de seguridad nacional, así como la forma en la que se han universalizado las medidas represivas, con el pretexto de la lucha antiterrorista, haciendo énfasis en una de sus causas, como es la vaguedad del concepto de terrorismo, en que claramente no se distingue entre los que atentan contra la seguridad del Estado y los que luchan por la defensa de los derechos humanos y el respeto de la democracia, permitiendo, de esta forma, que estos últimos sean judicializados como terroristas.

En la segunda parte, se analizará la situación de riesgo de defensores de derechos humanos, quienes han sido los encargados de poner al descubierto los excesos y los abusos de poder generados por la aplicación de estas políticas antiterroristas y que, al final, ha devenido una constante estigmatización y criminalización de su labor, provocando, en muchos casos, su judicialización bajo estas mismas políticas.

\section{TERRORISMO Y DERECHOS HUMANOS}

Desde los atentados terroristas del 11 de septiembre del 2001 en los Estados Unidos, del 11 de marzo del 2004 en Madrid y los de Londres el 7 y 21 de julio del 2005, muchas cosas no volverían a ser iguales. La conmoción mundial que se vivió después de estos ataques generó una sensación generalizada de miedo e inseguridad y, a partir de este momento, una nueva forma de terrorismo diferente de las ya conocidas, con capacidad de burlar los sistemas de seguridad más perfeccionados y actuar en cualquier parte del mundo, dejando a su paso el mayor número de víctimas posibles, se convertiría en el enemigo por combatir. ${ }^{1}$ Desde este contexto, se daría inicio al siglo xxI y, con ello, a la lucha frente a este nuevo terrorismo. ${ }^{2}$

Fue entonces la sensación de vulnerabilidad frente al peligro lo que provocó que los Estados tomaran iniciativas legislativas, para frenar esta oleada terrorista, fortaleciendo, de esta manera, su arsenal legal, con el firme propósito de prevenir y sancionar las acciones que venían de estos grupos o bien de endurecer su normativa antiterrorista existente. ${ }^{3}$

De esta forma, la lucha antiterrorista y el fortalecimiento de la seguridad se convirtió a partir de este momento en la prioridad de los Estados y, aunque legítima y necesaria, con el tiempo fue desviada de su objetivo principal y utilizada por muchos Estados para asegurar o reforzar su propio poder en detrimento de los compromisos que estos habían adquirido en favor de los derechos humanos. ${ }^{4}$

Al parecer, en esta nueva lucha, los Estados estaban dispuestos a regresar a la implementación de las viejas doctrinas de seguridad nacional desarrolladas durante la Segunda Guerra Mundial. ${ }^{5}$ Así, numerosos

1. Francisco Javier Pérez Royo y Manuel Carrasco Durán, Dirs. TerroRismo, Democracia y Seguridad, en Perspectiva constitucional. Marcial Pons. (2010). Ellos afirman: "La amenaza terrorista antes del 11 de septiembre de 2001 provenía de grupos delimitados, que tenían un ámbito de actuación específico, cuyos componentes provenían de círculos concretables y que actuaban según patrones de conducta también determinados, es decir, era en cierta medida algo predecible, aun dentro del contexto de incertidumbre e inseguridad. Los atentados del 11-S descubrieron al mundo un tipo de terrorismo causado por grupos con una estructura que podía hallarse dispersa, potencialmente en una multitud de lugares, grupos que actuaban desde diferentes países de manera semiautónoma y que tenían la capacidad de infiltrarse en cualquier Estado y pasar desapercibidos en medio de la sociedad hasta el momento de actuar. Apareció de esta forma un nuevo terrorismo global o internacional que incrementaba de manera exponencial la sensación de inseguridad que acompaña toda actividad terrorista".

2. José Manuel Rodríguez Uribes. LAS víctimas DeL terRorismo eN EsPaña. Editorial Dykinson. (2012).

3. Véase Pérez y Carrasco, supra, nota 1: "La primera iniciativa fue la $P a$ triot Act y la reclusión de los llamados enemigos combatientes en Guantánamo, y luego seguirían esa misma tendencia casi todos los Estados europeos que con la pretensión de reforzar la seguridad y de luchar contra el terrorismo, introdujeron severos límites a los derechos fundamentales. Esta tendencia se siguió al seno de organizaciones internacionales como Naciones Unidas y la Unión Europea, y finalmente frente a los atentados como los del 11 de marzo de 2004 en Madrid, los de Londres el 7 y 21 de julio de 2005 reforzaron esta tendencia”.

4. Federación Internacional de los Derechos Humanos [FIDH] y Organización Mundial Contra la Tortura [OMCT]. Los DEFensores DE DERECHOS HUMANOS EN PRIMERA LÍNEA. INFORME ANUAL. Éditions de l'aube. (2002).

5. Véase Édgar de Jesús Velásquez Rivera. Historia de la Doctrina de la Seguridad Nacional. Convergencia 27. Enero-abril de 2002: "La Doctrina de la Seguridad Nacional fue una ideología desde la cual Estados Unidos, 
Estados recibieron un verdadero cheque en blanco, una justificación, para la puesta en marcha de su estrategia represiva, incrementado sus poderes y atribuyendo otros más a las Fuerzas Militares, que, con el pretexto de luchar contra el terrorismo, han coartado el ejercicio de libertades fundamentales, en especial la personal, de locomoción, de expresión, asociación, de huelga y de manifestación. ${ }^{6}$

Sin embargo, por legítima y necesaria que sean estas políticas antiterroristas, hay algo que los Estados no han querido entender, y es que la implementación de estas políticas y la protección de los derechos humanos no son objetivos contrapuestos, sino complementarios que se deben reforzar mutuamente. ${ }^{7}$ El terrorismo sólo puede y debe combatirse desde el derecho, y cualquier otra solución genera toda clase de abusos y violaciones de los derechos humanos. ${ }^{8}$

En esta balanza, los Estados, al ponderar entre el respeto por los derechos humanos y la lucha contra el terrorismo, esta se inclinaba siempre hacia este último, lo que en muchos casos llevó a justificar la tortura y otros malos tratos en nombre de la lucha. ${ }^{9} \mathrm{Al}$ final, la prioridad que los Estados le dieron a la seguridad se tradujo en un aumento de las arbitrariedades y en un retroceso para los derechos humanos. ${ }^{10}$

\section{A. ¡En nombre de la lucha antiterrorista!}

Las primeras estrategias antiterroristas encaminadas a erradicar el terrorismo después de los ataques del 11 de septiembre fue la Patriot Act y la reclusión de los llamados enemigos combatientes en Guantánamo, y luego

después de la Segunda Guerra Mundial, consolidó su dominación sobre los países de América Latina, enfrentó la guerra Fría, fijó tareas específicas a las Fuerzas Armadas y estimuló un pensamiento político de derecha en los países de la región. Como ideología, reconoció sus orígenes en una visión bipolar del mundo desde la que, supuestamente, Occidente, liderado por los Estados Unidos, representaba el bien, la civilización, la democracia y el progreso; mientras que la entonces Unión Soviética estaba al frente del mal, el atraso y la dictadura”.

6. Véase FIDH y OMCT, supra, nota 4.

7. Javier Jordán, Pilar Pozo y Miguel Guindo, Eds. Terrorismo sin FRONTERAS. ACTORES, ESCENARIOS Y RESPUESTAS EN UN MUNDO GLOBAL. Thomson Reuters. (2010).

8. Fundación Seminario de Investigación para la Paz. Terrorismo, DEmocracia y Libertades. (2006). [De aquí en adelante Fundación Seminario].

9. Amnistía Internacional. Defender LOS DERechos humanos EN UN mundo CAmbiante. Editorial Amnistía Internacional. (2008). [De aquí en adelante Amnistía].

10. FIDH Y OMCT. LOS DEFENSORES DE DERECHOS HUMANOS FRENTE A LAS POLÍ́TICAS DE SEGURIDAD. INFORME ANUAL. (2003). seguirían esa misma tendencia casi todos los Estados europeos que, con la pretensión de reforzar la seguridad y de luchar contra el terrorismo, introdujeron fuertes límites a los derechos fundamentales. Esta tendencia se siguió en el seno de organizaciones internacionales, tales como las Naciones Unidas y la Unión Europea. ${ }^{11}$

También resulta preocupante el incremento en muchos Estados de leyes de seguridad ciudadana, elaboradas no como resultado de una política criminal estructurada, sino reactivamente a episodios coyunturales de enfrentamiento social y político que despiertan la sensación de utilizar la vía de la criminalización. ${ }^{12}$

De esta forma, la implementación de estas políticas daría paso a toda clase de abusos para lograr sus fines, entre ellos, tener carta abierta para poder intervenir las comunicaciones, allanar domicilios sin orden judicial, incrementar el control de circulación de las personas, recortar garantías judiciales, endurecer y ampliar las sanciones penales, dotar a las fuerzas militares de poderes judiciales, ${ }^{13}$ además de toda una serie de restricciones a las libertades fundamentales, muchas veces sobre la base de la simple sospecha de pertenecer a un grupo terrorista; ${ }^{14}$ al parecer, en nombre de la lucha contra la seguridad nacional, todos los abusos estaban justificados.

Además, estas prácticas basadas en el terrorismo como coartada conducen siempre al derecho de excepción, al derecho penal del enemigo, a combatir al terrorismo con los mismos o similares métodos, a combatir

11. Véase Fundación Seminario, supra, nota 8: "La Patriot Act norteamericana, de 26 de octubre de 2001, y la Antiterrorism, crime and security Bill, Británica, de 14 de diciembre de 2001 y otras medidas adoptadas por ambos Gobiernos, han derogado o suspendido algunos derechos fundamentales, convierten indiscriminadamente en sospechosos a todos los ciudadanos y en especial a los extranjeros, y permiten detener a estos sin cargos, incluso indefinidamente. La ley norteamericana autoriza a interceptar gubernativamente conversaciones telefónicas y electrónicas, a realizar registros domiciliarios secretos, a derogar el secreto de las comunicaciones entre los abogados y sus clientes, a imponer la censura en los medios de comunicación y a juzgar a los sospechosos en tribunales militares. Asimismo, en España las medidas antiterroristas son parte de una política represiva que se ve reflejada en las sucesivas reformas al Código Penal y de la Ley de Enjuiciamiento Criminal”.

12. Eduardo Rodríguez Veltzé y Farit L. Rojas Tudela. Criminalización y derecho a la protesta. Comp. Eduardo Bertoni. ¿Es LEGítimA LA CRIMINALIZACIÓN DE LA PROTESTA SOCIAL? DERECHO PENAL Y LIBERTAD DE EXPREsión en América Latina. Universidad de Palermo. (2010).

13. Véase FIDH y OMCT, supra, nota 10.

14. Luis de la Corte Ibáñez. LA LógiCA DEL Terrorismo. Alianza Editorial. (2006). Un caso extremo y digno de mención es el de los Gobiernos sudafricanos del apartheid, en cuyos documentos oficiales se podía leer que cualquier actividad que pusiera en peligro el mantenimiento de la ley y el orden podría ser definida como terrorista. 
el terror con más terror, a la implementación de políticas de miedo, que parecieran conducir a un contraterrorismo ilegal o, en el peor de los casos, a un terrorismo de Estado. ${ }^{15}$

\section{B. "Terrorismo", problema conceptual}

Una de las principales causas de estas políticas represivas se le atribuye a la vaguedad en el significado y alcance del concepto de terrorismo, pues su definición amplia y ambigua ${ }^{16}$ ha permitido que un gran número de actos, incluso aquellos que se dirigen a la defensa de los derechos humanos, caigan bajo el calificativo de terroristas.

Esta inseguridad jurídica no permite distinguir en la práctica qué y quiénes caen dentro de la denominación de terroristas, haciendo que su aplicación sea cada vez más discrecional. ${ }^{17}$ En muchos casos, pareciera que este término tiene un dueño que lo usa simplemente para descalificar a sus oponentes en la disputa por diversos tipos de hegemonías. ${ }^{18}$

El abuso en el concepto y en la identificación de muchos fenómenos violentos como terroristas es y ha sido una constante en la historia de la humanidad, ${ }^{19} \mathrm{y}$

15. Véase Rodríguez Uribes, supra, nota 2.

16. Véase Fundación Seminario, supra, nota 8. “Terrorista”, según el Diccionario de la lengua española, es un sustantivo (el que practica o el que es partidario del mismo) y un adjetivo (como en ataque terrorista, banda terrorista, o gobierno terrorista). Terrorismo, por su parte, puede ser un estado, una situación, una estructura en la que se practica esa dominación por el terror, y puede ser un proceso, es decir, una sucesión de actos en los que se observa la intención de infundir miedo ante un mal o peligro que se teme.

17. Id. Los elementos que componen la definición de la palabra terrorismo no son siempre los mismos. La violencia o la fuerza, lo político, el miedo o el énfasis en el terror, las amenazas, los efectos psicológicos, la discrepancia entre los grupos a los que va dirigido y las víctimas, la acción intencional planificada sistemática y organizada, estrategias y tácticas, son algunos de ellos.

18. Fundación Seminario de Investigación para la Paz. Afrontar el terrorismo. Terrorismo, guerra justa y argumentos.

19. Véase Rodríguez Uribes, supra, nota 2: "Por ejemplo recibieron ese calificativo estigmatizador, naturalmente desde las posiciones que los combatían, el terror jacobino, el método revolucionario o violento durante la Revolución francesa, o la resistencia contra el nazismo. También los de los montes o maquis fueron terroristas para Franco, o los Tupamaros en el Uruguay o la oposición en Chile para Pinochet; o para la Argentina de Videla los Montoneros, o incluso Trotski lo fue según Stalin; incluso en democracia se abusa del término. Eduard R. Murrow fue terrorista para el senador Joseph MacCarthy con el solo argumento de ser miembro de la OI (Internacional Obrera) y por tener un libro dedicado en los últimos años este calificativo de "terrorista" ha sido distorsionado para desacreditar a quienes se atreven a criticar sus políticas represivas. ${ }^{20}$

De esta manera, la lucha contra el terrorismo se convirtió en la "coartada" perfecta para que muchos Estados consolidaran su arsenal represivo y se afianzaran en el poder, ${ }^{21}$ muchas veces sin realizar ninguna distinción entre los que atentan contra la seguridad del Estado y los que luchan por la defensa de los derechos humanos y el respeto de la democracia. ${ }^{22}$

Frente a este dilema, los Estados siempre han contado con dos caminos para enfrentar el terrorismo, el primero y más extremo que justifica que para luchar contra el terrorismo cualquier método o medio es eficaz, así estos afecten los derechos humanos. Y el segundo que defiende que el terrorismo solo se debe combatir con el respeto por los derechos humanos y el fortalecimiento de la democracia. En los últimos años, pareciera que los Estados han escogido la primera opción y, en este propósito, todo aquel que se interponga en este camino se convertirá, de una u otra forma, en un obstáculo frente a esta lucha.

Ante esta opción, la lucha contra el terrorismo ha desencadenado toda una serie de violaciones contra los derechos humanos, que muchas organizaciones han salido a denunciar y defender, convirtiéndose en un obstáculo para los Estados frente a esta lucha contra el terrorismo.

de Harold Laski, el gran socialdemócrata fabiano. Y más recientemente, han recibido el estigma de terroristas los rebeldes de la llamada Primavera Árabe en la interpretación de cada uno de los dictadores afectados: Gadafi, Ben Ali el Tunecino, o Mubarak, incluida Siria”.

20. Véase FIDH y OMCT, supra, nota 4.

21. Véase Rodríguez Uribes, supra, nota 2: "El terrorismo como coartada se produce en estos casos de democracias consolidadas cuando en su lucha contra el terrorismo o so pretexto del terrorismo se olvidan de ciertos límites éticos y jurídicos que forman parte de la cultura de lo no negociable del Rul of law, de su moral interna en expresión de Fuller, y del discurso normativo de los derechos humanos. La Patriot Act o la Military Comisions Act de 2006 o el Documento sobre la Estrategia de Defensa Nacional de 2005, entre otros, son buenos ejemplos de terrorismo como coartada. Unas, normas que justifican la guerra total contra un terror igualmente total, una guerra perpetua y sin fin. En esa lógica perversa, los derechos humanos, y de entre ellos, las garantías procesales, deben ceder si es menester, si las circunstancias lo requieren".

22. Id. "Los derechos humanos aparecen siempre como la barrera moral y jurídica que los Estados no pueden franquear, no pueden eludir, tampoco en su combate necesario contra el terrorismo, so pena de practicar terror o contraterrorismo ilegal, una forma de terrorismo metodológico". 


\section{LA SITUACIÓN DE RIESGO DE LOS DEFENSORES Y DEFENSORAS DE DERECHOS HUMANOS}

La implementación de estas políticas antiterroristas pronto generaría graves violaciones de los derechos humanos, corrupción y abusos cometidos por la fuerza pública. Desde este contexto, la reacción de los Estados frente a estas revelaciones se enfocaría en desmentir a toda costa dichas acusaciones, para evitarse investigaciones por parte de los organismos de protección internacional de derechos humanos e impedir que su imagen pública resultara afectada.

De esta forma, la reacción de muchos Estados es poner en marcha estrategias legales de amordazamiento para controlar la información relacionada con abusos y excesos de poder, y así silenciar a quienes se atrevan a cuestionar sus prácticas represivas, impactando de forma directa la labor de defensa de los derechos humanos.

Desafortunadamente, esta labor de los defensores hoy más que nunca presenta muchos obstáculos y se encuentran en una situación de alto riesgo. Asesinatos, ejecuciones y desapariciones forzadas; agresiones, amenazas y hostigamientos; actividades de inteligencia y otras injerencias ilegales, arbitrarias o abusivas; la criminalización de su actividad a través del uso desproporcionado del derecho penal y leyes sancionatorias; el uso abusivo de la fuerza en manifestaciones de protesta social; las restricciones al ejercicio de la libertad de asociación y la impunidad en las investigaciones, son hoy los métodos utilizados para silenciar la labor de defensa de los derechos humanos. ${ }^{23}$

\section{A. La estigmatización y sus consecuencias}

La creciente caracterización de los defensores de los derechos humanos bajo etiquetas como "terroristas", "enemigos del Estado", "adversarios políticos", ${ }^{24}$ "rebeldes", "traidores de la nación",25 "insurgentes", "miembros de grupos izquierdistas", "antipatrióticos", 26

23. Comisión Interamericana de Derechos Humanos [CIDH]. Segundo INFORME SOBRE LA SITUACIÓN DE LAS DEFENSORAS Y DEFENSORES DE DERECHOS HUMANOS EN LAS AMÉRICAS. (2011).

24. Naciones Unidas. Comentario A LA DECLARACIÓN SOBRE EL DERECHO Y EL DEBER DE LOS INDIVIDUOS, LOS GRUPOS Y LAS INSTITUCIONES DE PROMOVER Y PROTEGER LOS DERECHOS HUMANOS Y LAS LIBERTADES FUNDAMENTALES UNIVERSALMENTE RECONOCIDAS. (2011).

25. FIDH y OMCT. El testimonio obstinado. Informe ANUAL. (2006). 26. FIDH y OMCT. La perseverancia del testimonio. Informe ANUAL. (2011): "De hecho, en Filipinas, Irán, Nepal, Pakistán, Sri Lanka "ilegales", "ilegítimos", "sin escrúpulos" "inmorales", "delincuentes", “corruptos", "mentirosos", "buscapleitos", "subversivos",27 "traficantes de derechos humanos", 28 "terroristas vestidos de civil", "agentes extranjeros manipulados por entidades transfronterizas", 29 "politiqueros al servicio del terrorismo", "voceros del terrorismo", 30 "nuevos criminales que deben ser neutralizados en nombre de la lucha antiterrorista" ${ }^{31} \mathrm{y}$, en muchas ocasiones, también acusados de "difundir propaganda nociva para el Estado", de "ser un peligro para la seguridad nacional", de "intentar derrocar al Gobierno", de "promover y sostener al terrorismo", de "fomentar un golpe de Estado", de "sedición", de ser "defensores de delincuentes", ${ }^{32}$ de "ser cómplices de grupos terroristas o guerrilleros" ${ }^{\prime \prime 3} \mathrm{y}$ de desempeñar un papel político que interfiere en los asuntos del Estado, apoyando los movimientos políticos opositores o los movimientos rebeldes, o aun estando al servicio de las potencias extranjeras. ${ }^{34}$

y Vietnam tachaban a los defensores de derechos humanos de 'terroristas', 'insurgentes', 'militantes', 'miembros de grupos izquierdistas' o 'antipatrióticos' y de 'actuar contra el país"'.

27. Amnistía Internacional. Transformar dolor en esperanza, DEFENSORAS Y DEFENSORES DE DERECHOS HUMANOS EN AMÉRICA. Editorial Amnistía Internacional. (2012): "Estigmatización y ataques a la reputación. Sin embargo, en todo el continente americano las defensoras y los defensores han sido tildados públicamente de 'ilegales', 'ilegítimos', 'sin escrúpulos' o incluso 'inmorales. También se los ha acusado de ser delincuentes, corruptos, mentirosos, buscapleitos o subversivos, de defender a delincuentes y de apoyar a grupos guerrilleros". [De ahora en adelante Amnistía]

28. Véase FIDH y OMCT, supra, nota 25: "La fórmula del presidente colombiano Álvaro Uribe, el 8 de septiembre, resume la situación: 'General, asuma el mando de las fuerzas aéreas para vencer al terrorismo. Que los traficantes de derechos humanos no le impidan, no le engañen, que toda la fuerza aérea colombiana preste a esta gran nación el servicio de liberarnos de una vez por todas de esa pesadilla".

29. FIDH y OMCT. VIOLACIONES DEL DERECHO DE LAS ONG A LA FINANCIACIÓN: DEL HOSTIGAMIENTO A LA CRIMINALIZACIÓN. INFORME ANUAL. (2013).

30. Véase Amnistía, supra, nota 27: "Estigmatización y ataques a la reputación. El primer mandatario declaró que algunos detractores del Gobierno eran 'politiqueros al servicio del terrorismo, que cobardemente se agitan en la bandera de los derechos humanos para tratar de devolverle en Colombia al terrorismo el espacio que la Fuerza Pública y que la ciudadanía le ha quitado [...]. Cada vez que en Colombia aparece una política de seguridad para derrotar el terrorismo, cuando los terroristas empiezan a sentirse débiles, inmediatamente envían a sus voceros a que hablen de derechos humanos"'.

31. Véase FIDH y OMCT, supra, nota 4.

32. Id.

33. Véase Naciones Unidas, supra, nota 24.

34. Véase FIDH y OMCT, supra, nota 4. 
Esta situación de criminalización en la que no solo las autoridades y los funcionarios públicos, a través de sus difamaciones sistemáticas los estigmatizan, sino ahora también los medios de comunicación, han declarado que esos defensores "manchan la reputación de la madre patria", "debilitaban el proceso democrático" y "arrebataban al Gobierno su prestigio". ${ }^{35}$ Como si esto fuera poco, en los últimos años, algunas empresas trasnacionales interesadas en la construcción de megaproyectos los califican de "opositores al desarrollo", de "amigos de la subversión" y "enemigos del progreso". ${ }^{36}$ Al final, el uso indiscriminado de etiquetas criminalizantes ha terminado calando en el imaginario social y ahora también la ciudadanía los percibe y califica como "perturbadores" ${ }^{37}$

Las consecuencias de estas declaraciones llevaron en muchos casos que los defensores de derechos humanos y sus familias corrieran grave riesgo de sufrir amenazas y represalias de grupos armados al margen de la ley, incluso de las mismas Fuerzas Armadas. ${ }^{38}$ Estas últimas sobre la base de una supuesta "guerra jurídica" que estarían desarrollando algunas ONG en contra de los miembros de la Fuerza Pública, por abusos y violaciones a los derechos humanos. ${ }^{39}$

35. Véase Naciones Unidas, supra, nota 24.

36. Misión Internacional. Misión INTERNACIONAL DE VERIFICACIÓN SOBRE LA SITUACIÓN DE LA DEFENSA DE LOS DERECHOS HUMANOS EN COLOMbia. (2011): “En Colombia la Misión pudo establecer que una nueva ola de señalamientos se está produciendo alrededor de las economías extractivas en contra de los defensores y defensoras de tierras y territorios, así como defensores/ras del medio ambiente, específicamente en los departamentos de Antioquia, Santander y Cauca fueron reiterativos los testimonios de defensores/ras en los que denuncian señalamientos de parte de la Fuerza Pública, funcionarios de las instituciones locales y regionales y las empresas privadas, en los que se los califica de 'opositores del desarrollo,' 'amigos de la subversión' y 'enemigos del progreso”'.

37. Véase CIDH, supra, nota 23.

38. Véase FIDH y OMCT, supra, nota 26: "En febrero de 2009, el Sr. Hollman Morris, quien realizaba un documental en el marco de la liberación de tres policías y un soldado por parte de las FARC, fue detenido y sometido a un interrogatorio por parte del Ejército y altos miembros del Gobierno colombiano que le exigían la entrega del material periodístico. Además, el presidente Uribe lo acusó públicamente de supuestos vínculos con el grupo insurgente. Luego de este señalamiento del presidente, el periodista recibió múltiples amenazas de muerte. Declaraciones de este tipo no solo significan una condena al ejercicio de la defensa de los derechos humanos, sino que coloca la vida de los defensores en serio peligro".

39. Véase Misión internacional, supra, nota 36: "Para la Misión es alarmante que se pretendan descalificar las denuncias legítimas interpuestas por casos de violaciones a los derechos humanos y al derecho internacional humanitario cometidas por miembros de la Fuerza Pública, argumentando que se trata de una 'guerra jurídica' que según miembros de la Fuerza Pública libran en su contra defensores/ras, organizaciones y asociaciones que tienen vínculos con la insurgencia o el narcotráfico".
Resulta claro, entonces, que este tipo de estigmatización pone en peligro la seguridad física y psicológica de los defensores ${ }^{40} \mathrm{y}$, a la vez, genera un clima de hostilidad que dificulta el ejercicio legítimo de la libertad de asociación de los demás defensores, en que el mensaje que se intenta transmitir es el del miedo, el de la abstención, el del silencio. ${ }^{41}$

A lo anterior hay que sumarle que en los últimos años se viene intencionalmente cuestionando la neutralidad de las organizaciones de defensa de los derechos humanos ${ }^{42}$ y deslegitimando la labor que desarrollan estas $\mathrm{ONG},{ }^{43}$ ya sea mediante la expulsión y persecución judicial de sus miembros, el allanamiento de sus sedes y ahora el control en el acceso para su financiación, buscando, de esta forma, reprimir toda forma de crítica y, en especial, silenciar de cualquier forma las llamadas al cambio democrático o al establecimiento de responsabilidades por violaciones de derechos humanos. ${ }^{44}$

Así las cosas, resulta preocupante la forma en que los defensores de los derechos humanos corren graves riesgos en el curso de sus esfuerzos para poner al descubierto los excesos y los abusos de poder, ${ }^{45}$ al ser mensajeros de verdades incómodas que, a menudo, los Gobiernos se esfuerzan sobremanera por ocultar. La función de las personas que defienden los derechos humanos siempre se considerará subversiva en países

\footnotetext{
40. Véase FIDH y OMCT, supra, nota 4.

41. Comisión Interamericana de Derechos Humanos [CIDH]. SEgundo INFORME SOBRE LA SITUACIÓN DE LAS DEFENSORAS Y DEFENSORES DE DERECHOS HUMANOS EN LAS AMÉRICAS. (2011).

42. Véase FIDH y OMCT, supra, nota 10.

43. Id. El 8 de septiembre de 2003, en un discurso pronunciado durante la Semana de los Derechos Humanos, con ocasión de la posesión del nuevo comandante de la Fuerza Aérea, el presidente Álvaro Uribe Vélez dividió de manera perniciosa a las ONG de defensa de los derechos humanos en tres categorías. Por una parte, las ONG “teóricas”; por otra parte las ONG llamadas "respetables”, que deben ser protegidas por el Estado, y finalmente un tercer grupo que fue presentado como el de las ONG de los "escritores y politiqueros que finalmente le sirven al terrorismo y que se escudan cobardemente en la bandera de los derechos humanos" y que por lo tanto no deberían recibir la protección del Estado. El presidente concluyó su discurso incitando al nuevo comandante de la Fuerza Aérea, el general Lesmez, a hacer caso omiso del respeto a los derechos humanos para vencer al terrorismo.

44. Véase FIDH y OMCT, supra, nota 29: "La posibilidad de que las asociaciones accedan a financiación y recursos es parte integrante y vital del derecho a la libertad de asociación [...] Todas las asociaciones, estén o no registradas, deben disfrutar del derecho a recabar y obtener financiación de entidades nacionales, extranjeras e internacionales, incluidos particulares, empresas, organizaciones de la sociedad civil, gobiernos y organizaciones internacionales".
}

45. Véase Amnistía, supra, nota 27. 
en los que estos derechos son poco más que una lista de compromisos sobre el papel. ${ }^{46}$

\section{B. ¡Ahora somos procesados como terroristas!}

Uno de los principales impedimentos que realmente obstaculizan la actividad de los defensores de derechos humanos es la forma en la que los Estados vienen implementando reglamentaciones y nuevas reformas al Código Penal, ${ }^{47}$ que al final han terminado por criminalizar su actividad, haciendo un uso desproporcionado del derecho penal y generando toda una serie de procesos judiciales sin fundamento, muchos de estos bajo el uso de tipos penales ya existentes, y otros que se han venido formulando de forma vaga y ambigua. ${ }^{48}$

Resulta habitual la iniciación infundada de acciones penales, prolongadas muchas veces en el tiempo, contra defensores de derechos humanos, por un supuesto ejercicio indebido de la libertad de pensamiento y expresión, así como del derecho de reunión y asociación, o la afectación a la honra o reputación de servidores públicos, sobre la base de acusaciones falsas e infundadas. ${ }^{49} \mathrm{~A}$ esto hay que sumarle la criminalización de los abogados defensores, que prestan asistencia jurídica a otros defensores o a las víctimas de violaciones de derechos humanos, quienes reciben amenazas y son detenidos y acusados de varios delitos. ${ }^{50}$

46. Véase Amnistía, supra, nota 9.

47. En algunos casos, las reformas al Código Penal han venido de la mano con la creación de nuevas reglamentaciones de seguridad ciudadana, que se han generado no como resultado de una política criminal elaborada y debidamente informada, sino reactivamente a episodios coyunturales de enfrentamiento social y político que despiertan la tentación de utilizar la vía de la criminalización. Una oleada global de dirección autoritaria se ha venido extendiendo; por ejemplo, en países como España, Reino Unido, Ucrania, Egipto, Canadá, hasta algunos países de América Latina, se viene amenazando de esta forma a la democracia y criminalizando el ejercicio del derecho a la protesta social, cuyo fin no es el de garantizarle seguridad a la sociedad, sino, por el contrario, infundirle miedo en la ciudadanía para que no luchen por la defensa de sus derechos.

48. Véase CIDH, supra, nota 41.

49. Id. Resulta inverosímil la asociación de la actividad de defensa de derechos humanos con la utilización de tipos penales como el de "asociación ilícita", "obstrucción de la vía pública", "incitación al delito", desobediencia", "amenaza a la seguridad del Estado", "la seguridad pública o la protección de la salud o moral públicas", "difamación", "calumnia", "rebelión", "sedición", incluso "terrorismo", ya que frente a tales delitos se inician procesos penales injustificados, permitiendo además un amplio margen de discrecionalidad a los jueces y autoridades encargadas de la acusación penal.

50. Sobre este tema, véase también Amnistía, supra, nota 27. "Estigmatización y ataques a la reputación. Un caso documentado por Amnistía Internacional es el de la ciudadana estadounidense Lynne Stewart. Conocida abogada penalista, de más de 60 años, Lynne Stewart fue acusada por
Por solo citar un caso, resulta preocupante la situación de Colombia, que en los últimos años pasó a convertirse en uno de los países en el mundo en que más se atenta contra la actividad de los defensores de derechos humanos..$^{51} \mathrm{Al}$ parecer, la confrontación del conflicto armado interno, que se ha prolongado por más de cincuenta años, viene justificando los métodos aplicados para ponerle fin.

De esta forma, muchos procesos penales se han iniciado sobre la base de informes de inteligencia, junto con testimonios no corroborados de desmovilizados o supuestos desmovilizados, ya sea de grupos paramilitares o grupos guerrilleros; estos primeros en procura de beneficios por la Ley 975 o Ley de Justicia y Paz. ${ }^{52}$ Así como el uso de informantes pagados por las Fuerzas Armadas, utilizados en varias ocasiones para iniciar procesos en contra de defensores de derechos humanos. ${ }^{53}$

En este contexto, la "guerra contra el terrorismo" en Colombia se destaca como el ejemplo más extremo, de la puesta en marcha de medidas supuestamente destinadas a combatir a los grupos armados ilegales, para perseguir, dar muerte y silenciar a los activistas de derechos humanos. ${ }^{54}$ las autoridades estadounidenses en abril de 2002 de proporcionar 'apoyo material' a una 'organización terrorista extranjera', delito que acarrea penas de prisión de hasta 40 años. Los cargos se relacionaban con sus contactos con uno de sus clientes, Sheik Omar Abdul Rahman, condenado en 1995 en relación con el atentado con explosivos cometido en 1993 en el World Trade Center y presuntas conspiraciones para colocar bombas en otros lugares importantes de EE. UU. Stewart era la abogada defensora que le habían asignado los tribunales y siguió representándolo después del juicio. Los cargos formulados contra Lynne Stewart se basaron en un artículo - rara vez utilizado en el pasado- de una ley antiterrorista de 1996 que penaliza el suministro de 'apoyo material' a cualquier grupo designado como 'organización terrorista extranjera'. Esta ley define el 'apoyo material' de una manera muy amplia y se ha venido usando de forma creciente desde el 11 de septiembre de 2001 para acusar a individuos que el gobierno considera vinculados al 'terrorismo"'.

51. Véase FIDH y OMCT, supra, nota 25.

52. Véase Misión internacional, supra, nota 36.

53. Id. El sistema de pago de informantes en áreas donde las oportunidades de empleo para los y las jóvenes son escasas, por no decir nulas, se constituye en una fuente de recursos que en muchas circunstancias no está ligada al propósito de brindar información verídica sobre actividades que afectan el orden público.

54. Véase Amnistía, supra, nota 27. 


\section{Conclusiones}

Finalmente, es necesario comprender que el terrorismo solo puede y debe combatirse desde el derecho, y cualquier otra solución contraria a este genera toda clase de arbitrariedades, abusos y violaciones de los derechos humanos.

La falta de claridad en el alcance del concepto de terrorismo no permite distinguir en la práctica qué y a quiénes se puede aplicar la denominación de terroristas, haciendo que su uso continúe siendo discrecional sobre quienes se empeñan en denunciar los abusos y excesos de los Estados en la aplicación de estas políticas antiterroristas.

Por último, a pesar de esta situación de especial riesgo, la estigmatización, criminalización y judicialización de los defensores de derechos humanos, el objetivo principal sí es convertirse en un obstáculo para los Estados represivos, que desconocen la importancia del respeto por los derechos humanos.

\section{REFERENCIAS}

Amnistía Internacional. Defender los Derechos humaNOS EN UN MUNDO CAMBiante. Editorial Amnistía Internacional. (2008).

Amnistía Internacional. TRANSFORMAR DOLOR EN ESPERANZA, DEFENSORAS Y DEFENSORES DE DERECHOS HUMANOS EN AMÉRICA. Editorial Amnistía Internacional. (2012).

Comisión Interamericana de Derechos Humanos [CIDH]. Segundo Informe sobre la situación de LAS DEFENSORAS Y DEFENSORES DE DERECHOS HUMANOS EN LAS AMÉRICAS. (2011).

Édgar de Jesús Velásquez Rivera. Historia de la doctrina de la seguridad nacional. Convergencia 27. Enero-abril de 2002.

Eduardo Rodríguez Veltzé y Farit L. Rojas Tudela. Criminalización y derecho a la protesta. Comp. Eduardo Bertoni. ¿ES LEGítima LA CRIMINALIZACIÓN DE LA PROTESTA SOCIAL? DeRecho PENAL y LIBERTAD DE EXPRESIÓN en América Latina. Universidad de Palermo. (2010).
Federación Internacional de los Derechos Humanos [FIDH] y Organización Mundial Contra la Tortura [OMCT]. LOS DEFENSORES DE DERECHOS HUMANOS EN PRIMERA LÍNEA. INFORME ANUAL. Éditions de l’aube. (2002).

Federación Internacional de los Derechos Humanos [FIDH] y Organización Mundial Contra la Tortura [OMCT]. LOS DEFENSORES DE DERECHOS HUMANOS FRENTE A LAS POLÍTICAS DE SEGURIDAD. INFORME ANUAL. (2003).

Federación Internacional de los Derechos Humanos [FIDH] y Organización Mundial Contra la Tortura [OMCT]. El testimonio obstinado. Informe anUAL. (2006).

Federación Internacional de los Derechos Humanos [FIDH] y Organización Mundial Contra la Tortura [OMCT]. El testimonio obstinado. Informe ANUAL. (2007).

Federación Internacional de los Derechos Humanos [FIDH] y Organización Mundial Contra la Tortura [OMCT]. LA PERSEVERANCIA DEL TESTIMONIO. INFORME ANUAL. (2011).

Federación Internacional de los Derechos Humanos [FIDH] y Organización Mundial Contra la Tortura [OMCT]. VIOLACIONES DEL DERECHO DE LAS ONG A LA FINANCIACIÓN: DEL HOSTIGAMIENTO A LA CRIMINALIZACIÓN. INFORME ANUAL. (2013).

Francisco Javier Pérez Royo y Manuel Carrasco Durán, Dirs. Terrorismo, Democracia y Seguridad, en Perspectiva Constitucional. Marcial Pons. (2010).

Fundación Seminario de Investigación para la Paz. TerroRISMO, DEMOCRACIA Y LIBERTADES. (2006).

Javier Jordán, Pilar Pozo y Miguel Guindo, Eds. Terrorismo SIN FRONTERAS. ACTORES, ESCENARIOS Y RESPUESTAS EN UN MUNDO GLOBAL. Thomson Reuters. (2010).

José Manuel Rodríguez Uribes. LAS víctimas DEL TERRORISMO EN ESPAÑA. Editorial Dykinson. (2012).

Luis de la Corte Ibáñez. LA LóGICA DEL TERrorismo. Alianza Editorial. (2006).

Misión Internacional. Misión INTERNACIONAL DE VerifiCACIÓN SOBRE LA SITUACIÓN DE LA DEFENSA DE LOS DERECHOS hUMANOS EN COLOMBIA. (2011).

Naciones Unidas. Comentario a LA DEClaración SOBRE EL DERECHO Y EL DEBER DE LOS INDIVIDUOS, LOS GRUPOS Y LAS INSTITUCIONES DE PROMOVER Y PROTEGER LOS DERECHOS HUMANOS Y LAS LIBERTADES FUNDAMENTALES UNIVERSALMENTE RECONOCIDAS. (2011). 